\title{
Microanalysis Standards and Instrumental Calibration: Practical Improvements in Analytical Confidence
}

\section{P. K. Carpenter}

Earth and Planetary Sciences, CB 1169, Washington University, St. Louis, MO 63130

Electron-probe microanalysis (EPMA) can in principle use a minimal set of standards to analyze diverse compounds over the entire concentration range. Careful measurement procedures result in precise analyses, and accuracy relative to a set of primary standards is evaluated through use of secondary standards. The inspection of analyses on secondary standards is the main test an analyst has to evaluate accuracy. Few studies have evaluated accuracy for multielement mineral and glass standards, but analysts quote accuracy of approximately $2-5 \%$ when questioned. Is this figure correct and how are sets of standards evaluated in an objective manner?

Certification testing of NIST SRM 481 AuAg binary alloys utilized relations between measured $\mathrm{k}$ and known $\mathrm{C}$ (where $\mathrm{k}=(\mathrm{P}-\mathrm{B})^{\mathrm{smp}} /(\mathrm{P}-\mathrm{B})^{\mathrm{std}}$ and $\mathrm{C}$ is concentration) to demonstrate the internal consistency and accuracy of EPMA measurements at multiple accelerating potential (FIG 1A)[1]. Kratio measurements on binary alloys of known composition have been used to develop correction algorithms in order to minimize the difference between measured and calculated k-ratio (FIG 1B), and these plots again demonstrate consistency in the compositional data set [2]. However, there are few if any published k-ratio data on multi-element mineral standards, and there is typically anecdotal evidence concerning estimates of accuracy for these materials.

Procedures used to evaluate the alignment of multiple x-ray spectrometers can also be used to test the agreement of microanalysis standards. All spectrometers on a properly aligned instrument should measure identical k-ratios $k^{e x p}$ relative to a set of pure element, oxide, or silicate standards. Further, these $k^{\text {exp }}$ should equal calculated k-ratios $k^{\text {corr }}$ obtained using correction algorithms with valid data sets (e.g., mass absorption coefficients). A plot of $\mathrm{k}^{\mathrm{exp}} / \mathrm{k}^{\text {corr }}$ vs. weight percent of each element reveals systematic errors in instrumental or compositional aspects, and the use of multiple spectrometer data simplifies detection of instrumental problems while errors in composition or correction should apply systematically to all measured values. The use of this plot thus demonstrates internal consistency of the standards used if the instrument is performing properly. This approach provides significant confidence in measurement on an instrument and has revealed systematic errors in spectrometer alignment and the composition of standards in the suite. A suite of mineral standards has been used for this purpose, and includes compositions in the Ca-Mg-Al-Si-Ti-Fe (CMASTF) compositional system (FIG 1C). This suite of standards was analyzed by both EDS and WDS methods using primary standards $\mathrm{CaSiO}_{3}, \mathrm{MgO}, \mathrm{Al}_{2} \mathrm{O}_{3}, \mathrm{SiO}_{2}, \mathrm{TiO}_{2}$, and $\mathrm{Fe}_{2} \mathrm{O}_{3}$. Measurements were made on a JEOL JXA-8200 microprobe with 5 WDS spectrometers and an E2V-Gresham SDD EDS detector, using the Probe for EPMA analysis software, and were obtained at $15 \mathrm{kV}, 25 \mathrm{nA}$, and 10-20 um defocused beam. Repeaking of the WDS spectrometer was necessary for $\mathrm{Mg}$, $\mathrm{Si}$, and $\mathrm{Al}$ for phases where a peak shift is observed due to bonding effects. All analyses were corrected using the Armstrong $\Phi(\rho z)$ algorithm with "LINEMU" macs of Probe for EPMA (Henke, Henke and Ebisu, and Heinrich). 
The results indicate excellent accuracy and agreement among the chosen standards for major and minor element concentrations, but for trace elements errors are observed for some standards that are well out of the range of counting statistics (FIG $2 \mathrm{~A}$ and $2 \mathrm{~B}$ ). The accepted composition for $\mathrm{Al}$ in Weill glass $\mathrm{E}$ (nominal $8.99 \% \mathrm{Al}_{2} \mathrm{O}_{3}$ ) is incorrect by $15 \%$ relative, when viewed with all analytical data. The accuracy of all WDS analyses expressed in $1 \sigma$ percent of $\mathrm{k}^{\mathrm{exp}} / \mathrm{k}^{\mathrm{corr}}$ ranges from $0.6-2.27 \%$ with most values less than $1 \%$. Thus the relative accuracy of the standard analyses is as good as $1 \%$ relative. Results from SDD EDS analyses will also be presented.

\section{References}

[1] Heinrich KFJ et al. NBS Special Publication 260-28. 1971.

[2] Pouchou, JL, and Pichoir, F. in Electron Probe Quantitation, KFJ Heinrich and DE Newbury, eds. Plenum, New York, 1991.

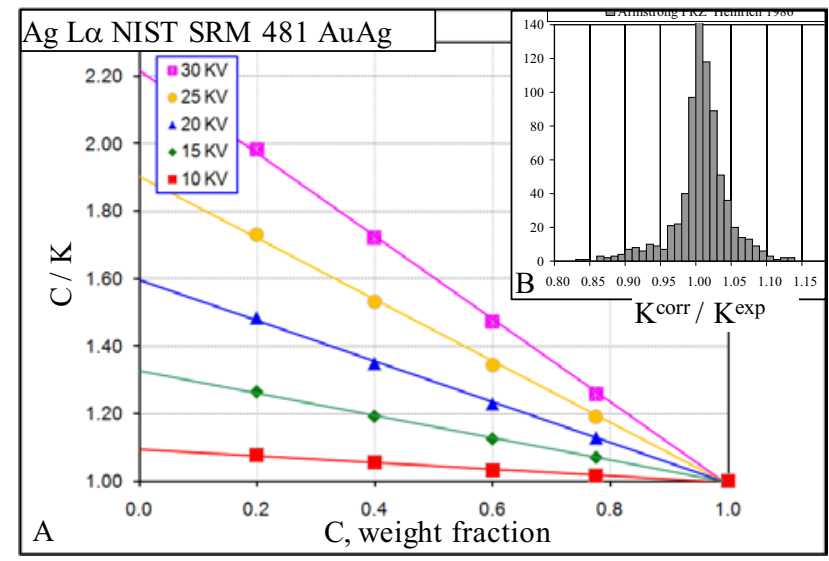

\begin{tabular}{|c|c|c|c|c|c|c|}
\hline C standard & MgO & $\mathrm{A} 12 \mathrm{O} 3$ & $\mathrm{SiO}_{2}$ & $\mathrm{CaO}$ & $\mathrm{TiO} 2$ & $\begin{array}{l}\mathrm{FeO}^{*} \text { or } \\
\mathrm{Fe}^{2} \mathrm{O} 3\end{array}$ \\
\hline Alaska Anorthite & & 36.03 & 44.00 & 19.09 & & 0.62 \\
\hline Boyd Olivine & 51.63 & & 40.85 & & & 7.17 \\
\hline Ilmen Mtas Ilmenite & 0.31 & & & & 45.70 & 46.54 \\
\hline K411 Glass & 14.67 & 0.10 & 54.30 & 15.47 & & 14.42 \\
\hline K412 Glass & 19.33 & 9.27 & 45.35 & 15.25 & & 9.96 \\
\hline Kyanite P236 & & 62.91 & 37.09 & & & \\
\hline Natural Bridge Diopside & 18.31 & 0.06 & 55.40 & 25.78 & 0.01 & 0.26 \\
\hline ORNL, RDS Fayalite & & & 29.49 & & & 70.51 \\
\hline San Carlos Otivine & 49.42 & & 40.51 & & & 9.55 \\
\hline Shankland Forsterite & 57.30 & & 42.70 & & & \\
\hline Springwater Olivine & 43.58 & & 38.95 & & & 16.62 \\
\hline Taylor Kyanite & 0.00 & 62.70 & 37.00 & & & 0.16 \\
\hline Taylor Olivine & 50.78 & & 41.15 & & & 7.62 \\
\hline Taylor Sphene & & 1.36 & 30.83 & 28.82 & 37.80 & 0.66 \\
\hline Taylor Spinel & 28.34 & 71.66 & & & & \\
\hline Weill A & 11.05 & 16.07 & 49.72 & 23.15 & & \\
\hline Weill B & 13.99 & 16.05 & 48.99 & 20.97 & & \\
\hline Weill D & 17.97 & 20.96 & 45.07 & 16.00 & & \\
\hline Weill $\mathrm{E}^{*}$ & 6.00 & 8.99 & 79.97 & 5.04 & & \\
\hline Weill Enstatite Glass & 40.15 & 0.00 & 59.85 & & & \\
\hline Weill $\mathbf{F}$ & 10.07 & 30.93 & 52.06 & 6.94 & & \\
\hline Weill G & 32.69 & 3.31 & 61.12 & 2.59 & & \\
\hline Weill $\mathbf{H}$ & 5.22 & 41.90 & 30.91 & 21.97 & & \\
\hline Weill I & 19.03 & 2.01 & 52.95 & 26.01 & & \\
\hline Weill $\mathrm{J}$ & 1.01 & 19.02 & 42.98 & 36.99 & & \\
\hline
\end{tabular}

FIG 1 A K-ratio data for Ag L $\alpha$ in NIST SRM 418 AuAg alloys at 40 degree takeoff angle. Plots demonstrate internal consistency of experimental measurements and confirm AuAg concentrations. B Histogram of calculated k-ratios relative to experimental k-ratios for Pouchou binary alloy set $(n=900)$, corrected using Armstrong $\Phi(\rho z)$ algorithm and Heinrich 1986 macs. C Composition of standards used in Ca-Mg-Al-Si-Ti-Fe suite.

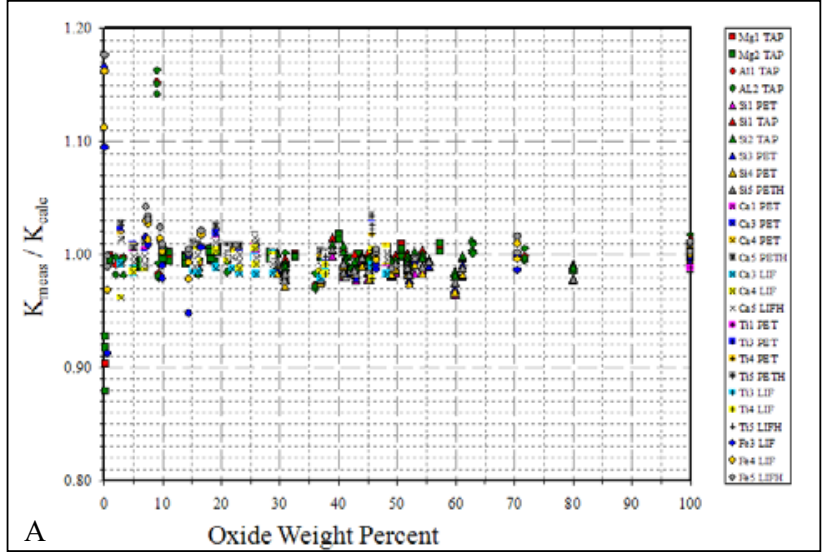

\begin{tabular}{|c|c|c|c|c|c|}
\hline B wDS & Spec 1 & Spec 2 & Spec 3 & Spec 4 & Spec 5 \\
\hline Mg TAP & 0.65 & 1.30 & & & \\
\hline Al TAP & 1.06 & 1.22 & & & \\
\hline Si TAP & 0.74 & 0.64 & & & \\
\hline Si PET & 0.71 & & 0.71 & 0.75 & 0.70 \\
\hline Ca PET & 0.79 & & 0.73 & 0.70 & 0.74 \\
\hline Ca LiF & & & 0.74 & 0.92 & 0.69 \\
\hline TiPET & 2.27 & & 1.44 & 0.98 & 1.54 \\
\hline TiLiF & & & 0.61 & 1.15 & 1.14 \\
\hline Fe LiF & & & 1.75 & 1.27 & 1.26 \\
\hline
\end{tabular}

FIG 2 A Plot of $K^{\exp } / K^{\text {corr }}$ vs. oxide weight percent for all WDS measurements on CMASTF standards data set. Note outlier for $\mathrm{Al}$ in glass Weill $\mathrm{E}$ is clearly incorrect in comparison to all analyses. B Accuracy of WDS analyses of CMASTF standards set, expressed in $1 \sigma$ relative $\%$ in error of $\mathrm{K}^{\mathrm{exp}} / \mathrm{K}^{\text {corr }}$. 